\title{
KADAR DEBU UDARA PADA BAGIAN PRODUKSI UD.MANDIRI DI DESA TELUK KECAMATAN PURWOKERTO SELATAN KABUPATEN BANYUMAS TAHUN 2018
}

\author{
Nisa Adelia 1), Tri Marthy Mulyasari ${ }^{2)}$ \\ Jurusan Kesehatan Lingkungan, Politeknik Kesehatan Kemenkes Semarang, \\ Jl.Raya Baturaden KM 12 Purwokerto, Indonesia
}

\begin{abstract}
Abstrak
Kualitas udara dipengaruhi oleh banyak hal, salah satunya adalah polutan. Industri kayu merupakan salah satu industri yang menghasilkan polutan berupa debu. Pekerja yang terpajan debu memiliki risiko untuk mengalami keluhan kesehatan dan penyakit, baik penyakit infeksi maupun non infeksi (kanker). Tujuan penelitian ini adalah untuk mengukur kadar debu, suhu, kelembapan, kecepatan angin dan arah angin pada bagian produksi UD.Mandiri Di Desa Teluk Kecamatan Purwokerto Selatan Kabupaten Banyumas. Jenis penelitian ini adalah deskriptif. Pengumpulan data dilakukan dengan wawancara, kuesioner, dan dokumentasi. Data disajikan dalam bentuk tabel, gambar dan narasi. Hasil penelitian menunjukkan bahwa pengukuran kadar debu total pada bagian produksi UD.Mandiri didapatkan hasil rerata 2,12 mg/m3, melebihi standar Permenkes Nomor 70 Tahun 2016 pada tempat kerja kadar debu tertinggi diperkenankan adalah 10 $\mathrm{mg} / \mathrm{m}^{3}$. Pengukuran suhu udara didapatkan hasil rerata $33,2^{\circ} \mathrm{C}$ melebihi standar $\left(24^{\circ} \mathrm{C}-26^{\circ} \mathrm{C}\right)$, pengukuran kelembaban udara didapatkan hasil 58,8\% dibawah standar (65\%-95\%), pengukuran kecepatan angin didapatkan hasil $0,16 \mathrm{~m} / \mathrm{s}$ sesuai standar $(0,15-0,25 \mathrm{~m} / \mathrm{s})$, arah angin dominan ke arah Timur Laut. Kesimpulan yaitu kadar debu total pada bagian produksi UD.Mandiri melebihi standar Permenkes Nomor 70 Tahun 2016, suhu udara melebihi standar, kelembaban udara dibawah standar, kecepatan angin sesuai standar, arah angin dominan ke arah Timur Laut. Upaya yang dapat dilakukan untuk mengendalikan kadar debu pada bagian produksi yaitu dengan memasang vacuum cleaner (penyedot debu), pemilik menyediakan alat pelindung diri yang sesuai dengan risiko bahaya yang ada pada bagian produksi.
\end{abstract}

Kata kunci: Udara, debu, kayu.

\begin{abstract}
Air quality is influenced by many things, one of which is pollutants. Wood industry is one of the industries that produce pollutants in the form of dust. Dust-exposed workers are at risk for health and disease complaints, both infectious and non-infectious diseases (cancer). The purpose of this research is to measure the dust, temperature, humidity, wind speed and wind direction in production section of UD. Mandiri In Teluk Village of South Purwokerto Sub District Banyumas District. The type of research used is descriptive. The data were collected through interviews, questionnaires, and documentation. Data is presented in the form of tables, drawings and narratives. The research results total dust content in production UD.Mandiri got the result of average $2,12 \mathrm{mg} / \mathrm{m}^{3}$ unders the standard Permenkes $\mathrm{No} .70$ of 2016 at work place the highest dust content is allowed is $10 \mathrm{mg} / \mathrm{m}^{3}$. Measurement of air temperature got the result of average $33,2^{\circ} \mathrm{C}$ exceeds standard $\left(24^{\circ} \mathrm{C}-26^{\circ} \mathrm{C}\right)$. Measurement of air humidity got the result of average $58,8 \%$ under standard (65\%-95\%), Measurement wind speed got the result of average 0,16 m/s standard wind speed (0,15-0,25 $\mathrm{m} / \mathrm{s})$, result of wind direction determination more dominant towards the Northeast. The conclusion is total dust content in production UD.Mandiri exceeds the standard Permenkes No. 70 of 2016, air temperature exceeds standard, air humidity under standard, standard wind speed, dominant wind to the Northeast. Efforts that can be made to control the dust levels in the production section are by vacuum cleaner, the owner provides personal protective equipment in accordance with the hazards present in the production section.
\end{abstract}

Keyword: Air; Dust; Wood.

${ }^{1)}$ Email: nisaadelia03@gmail.com

${ }^{2)}$ Email: trimarthymulyasari@gmail.com 


\section{PENDAHULUAN}

Masalah pengotoran udara sudah lama menjadi masalah kesehatan pada masyarakat. Pembangunan yang berkembang pesat khususnya dalam bidang industri dan teknologi menyebabkan terjadinya perubahan komposisi udara melampaui daya dukung lingkungan, hal ini dapat berdampak negatif pada manusia, yaitu pencemaran udara dan polusi. Polusi atau pencemaran udara adalah masuknya komponen lain ke dalam udara, baik oleh kegiatan manusia secara langsung, tidak langsung, atau akibat proses alam sehingga kualitas udara turun sampai ketingkat tertentu yang menyebabkan lingkungan menjadi kurang kondusif, setiap substansi yang merupakan bagian dari komposisi udara normal disebut sebagai polutan (Chandra, 2006).

Kualitas udara dipengaruhi oleh banyak hal, salah satunya adalah polutan. Polutan dapat berasal dari pembakaran, pemanasan, kegiatan transportasi, dan industri. Polutan tersebut sebagian akan tertinggal di udara dan mempengaruhi kualitas lingkungan di sekitarnya, sedangkan sebagian lain akan terbawa angin (Department for Environmental Food \& Rural Affairs, 2014).

Industri kayu merupakan salah satu industri yang menghasilkan polutan berupa debu. Debu adalah partikel padat yang berasal dari pemecahan suatu bahan, baik yang berasal dari kegiatan manusia maupun proses alam (Mukono, 2003). Debu kayu tersusun dari senyawa lignin, holoselulosa (selulosa dan hemiselulosa), dan senyawa karbohidrat dalam jumlah yang rendah. Oleh sebab itu, debu kayu digolongkan ke dalam debu organik (Suma'mur, 2009).

Keberadaan debu di udara akan mengakibatkan terjadinya pencemaran udara. Pencemaran udara adalah terdapatnya bahan, zat, atau komponen lain di dalam udara yang menyebabkan perubahan susunan udara (Wardhana, 2004). Dampak pencemaran udara ini dapat terjadi pada berbagai aspek kehidupan. Bagi atmosfer, pencemaran udara akan menyebabkan terjadinya hujan asam dan mempercepat pemanasan global. Dari segi ekonomi, pencemaran udara akan meningkatkan biaya pemeliharaan alat dan bangunan serta biaya perawatan penyakit akibat pajanan polutan. Sedangkan dari segi kesehatan, pencemaran udara akan memicu timbulnya penyakit akut dan kronis (Mukono, 2003).

Pekerja yang terpajan debu memiliki risiko untuk mengalami keluhan kesehatan dan penyakit, baik penyakit infeksi maupun non infeksi (kanker). Keluhan pernapasan merupakan masalah kesehatan yang paling banyak dijumpai dalam industri kayu. Selain keluhan pernapasan, dampak pajanan debu terhadap kesehatan yang sering dilaporkan adalah dermatitis, gangguan fungsi paru, dan beberapa jenis kanker pada saluran pernapasan. Mikroorganisme yang terdapat pada kayu juga dapat menyebabkan terjadinya keluhan dan gangguan kesehatan (Irjayanti, dkk., 2012).

Keluhan pernapasan yang terjadi dipengaruhi oleh ukuran debu. Debu yang berukuran 5-10 mikron akan masuk ke dalam saluran napas atas, 3-5 mikron masuk ke dalam saluran napas tengah, 1-3 mikron dapat mencapai pembuluh di alveoli, 0,5-1 mikron akan menempel di alveoli, dan debu yang berukuran 0,1-0,5 akan melayang di atas alveoli (Depkes, 2014). Berbagai keluhan seperti hidung tersumbat, batuk, rinitis, dan asma juga dapat dialami oleh pekerja di industri kayu (Mirza, 2010).

UD. Mandiri merupakan pabrik kayu yang berlokasi di Jalan Sultan Agung Desa Teluk Kecamatan Purwokerto Selatan, yang sudah beroperasi sejak tahun 2005 dengan jumlah pekerja sebanyak 6 orang. UD. Mandiri melayani pembuatan kusen, jendela, pintu, perabot rumah tangga dan kantor. Bahan kayu yang tersedia diantaranya ada kayu jati, kamper, kruing dan kayu jawa. UD. Mandiri berpotensi untuk menimbulkan kontaminasi pencemaran udara di tempat kerja berupa debu kayu yang dihasilkan dari proses produksi.

Dampak negatif industri pengolahan kayu adalah pencemaran udara yang timbul pada proses pengolahan. Debu kayu ini akan mencemari daerah industri dan lingkungan sehingga pekerja maupun masyarakat di sekitar industri dapat terpapar oleh debu baik karena bahan baku, bahan antara ataupun produk akhir, karena bahan tercemar tersebut dapat berpengaruh terhadap lingkungan dan manusia.

Berdasarkan survey pendahuluan yang telah dilakukan pada pekerja dan lingkungan sekitar UD. Mandiri dapat dilihat pada daun di lingkungan sekitar pabrik yang tertutup debu dan pekerja yang bekerja di bagian produksi juga belum menggunakan masker sebagai alat pelindung diri sehingga pekerja berisiko menghirup debu kayu yang dapat menyebabkan gangguan pernafasan. Selain itu, belum pernah dilakukan pengukuran kadar debu udara di UD. Mandiri. Berdasarkan uraian diatas, maka peneliti akan mengadakan penelitian dengan Judul "Kadar Debu Udara Pada Bagian Produksi UD. Mandiri di Desa Teluk Kecamatan Purwokerto Selatan Kabupaten Banyumas Tahun 2018"

\section{BAHAN DAN METODE}

Jenis penelitian yang digunakan adalah penelitian deskriptif, yaitu suatu metode penelitian yang dilakukan dengan tujuan untuk membuat gambaran tentang kadar debu udara pada bagian produksi di UD.Mandiri Desa Teluk Kecamatan Purwokerto Selatan Tahun 2018 dengan menggunakan pendekatan crossectional. 
Populasi dan sampel. Populasi pada penelitian ini adalah udara pada bagian produksi pabrik kayu UD. Mandiri Desa Teluk Kecamatan Purwokerto Selatan.Sampel penelitian sebanyak lima titik sampel udara pada bagian produksi pabrik kayu UD. Mandiri Desa Teluk Kecamatan Purwokerto Selatan.

Jenis data yang digunakan adalah data umum dan data khusus. Data umum dari penelitian ini didapatkan dari hasil wawancara berupa wilayah geografis, hasil produksi, wilayah pemasaran, jumlah pekerja, lama kerja, peralatan kerja, bahan baku, proses produksi. Data khusus dalam penelitian ini berupa hasil pengukuran suhu, kelembapan, arah angin, kecepatan angin, kadar debu udara pada bagian produksi di UD. Mandiri Desa Teluk Kecamatan Purwokerto Selatan.

Sumber data dari penelitian ini adalah data primer dan data sekunder. Data primer diperoleh dari hasil pengukuran kadar debu udara, suhu, kelembapan, arah angin, kecepatan angin pada bagian produksi pembuatan kusen pintu dan jendela UD. Mandiri Desa Teluk Kecamatan Purwokerto Selatan. Data sekunder diperoleh dari pemilik pabrik kayu pembuatan kusen pintu dan jendela UD. Mandiri Desa Teluk Kecamatan Purwokerto Selatan data yang diambil meliputi wilayah geografis, hasil produksi, wilayah pemasaran, jumlah pekerja, lama kerja, peralatan kerja, bahan baku, proses produksi.

Pengumpulan data dilakukan dengan cara wawancara, pengukuran dan dokumentasi. Wawancara dilakukan dengan cara melakukan tanya jawab secara langsung kepada pemilik pabrik kayu pembuatan kusen pintu dan jendela UD. Mandiri Desa Teluk Kecamatan Purwokerto Selatan. Pengukuran merupakan salah satu metoda / kegiatan pengambilan data dengan mengukur secara langsung parameter yang diinginkan, yaitu kadar debu udara, suhu, kelembapan, arah angin, kecepatan angin. Dokumentasi yaitu mencatat dokumen-dokumen yang ada di pabrik kayu pembuatan kusen pintu dan jendela UD. Mandiri Desa Teluk Kecamatan Purwokerto Selatan. Intrumen pengumpulan data yang digunakan pada penelitian ini adalah dusttrak, thermohygrometer, anemometer, dan kuesioner.

Pengolahan data dilakukan dengan cara Editing, yaitu menyeleksi dan mengoreksi data yang telah dikumpulkan sesuai dengan kelompoknya. Cooding, yaitu pengelompokan data semua hasil pengukuran pada masing-masing data yang mempunyai kategori sama. Saving, yaitu penyimpanan data yang telah diperoleh dari hasil pengukuran.

Analisis data yang dilakukan dalam penelitian ini adalah dengan cara menyajikan hasil penelitian dalam bentuk tabel, narasi dan dilakukan analisis univariat dengan membandingkan dengan baku mutu Peraturan Menteri Kesehatan Nomor 70
Tahun 2016 tentang Standar dan Persyaratan Kesehatan Lingkungan Kerja Industri.

Etika penelitian yang digunakan adalah Lembar perijinan penelitian (Informed Consent), lembar perijinan penelitian diberikan kepada perusahaan atau tempat kerja, tujuannya agar perusahaan mengetahui maksud dan tujuan penelitian. Kerahasiaan (Confidentiality), semua data yang diperoleh dari dalam penelitian ini disetujui oleh pemilik pabrik kayu UD. Mandiri dan dijamin kerahasiaannya oleh peneliti hanya untuk kepentingan KTI tidak dipublikasikan. Tanpa nama (Annonimity), kerahasiaan identitas responden perlu dijaga peneliti tidak menuliskan identitas responden secara lengkap di lembar penelitian, nama dicantumkan dalam inisial huruf kemudian lembar tersebut hanya diberi nomer kode tertentu.

\section{HASIL DAN PEMBAHASAN}

\section{A. Data umum}

UD.Mandiri merupakan pabrik kayu penghasil kusen, pintu, jendela, lemari, kursi dan berbagai perabotan rumah tangga lainnya. UD.Mandiri sudah berdiri sejak tahun 2005 dan berlokasi di Jalan Sultan Agung Desa Teluk Kecamatan Purwokerto Selatan Kabupaten Banyumas. Pabrik yang dimiliki Bapak Slamet ini memiliki pekerja sebanyak 6 orang dengan luas lahan sebesar $560 \mathrm{~m}^{2}$.

UD.Mandiri terbagi menjadi beberapa bagian seperti bagian penyimpanan bahan baku, bagian produksi, penyimpanan produk jadi, dan kantor untuk kepentingan pemasaran. Bagian antar proses pada UD.Mandiri tidak mempunyai dinding pembatas sehingga hasil dari proses produksi yang berupa debu akan mudah menyebar dengan hembusan angin. Ruang produksi memiliki luas sebesar $300 \mathrm{~m}^{2}$ dengan panjang 30 meter dan lebar 10 meter.

Ruang produksi tidak memiliki cukup ventilasi, karena ventilasi hanya terletak pada bagian belakang ruangan berupa ventilasi buatan yang terbuat dari bambu yang disusun beronggarongga. Dinding pada ruang produksi belum sepenuhnya terbuat dari tembok, dinding tembok hanya pada bagian timur dan barat pabrik untuk bagian utara dan selatan dinding masih semi permanen/setengah tembok atau pasangan batu bata yang tidak diplester/papan.

Atap pada ruang produksi belum memiliki langit-langit. Lantai pada bagian depan pabrik sudah menggunakan batako namun untuk bagian produksi lantai masih berupa semen plesteran yang retak dan berdebu. Pintu utama berada pada sebelah utara pabrik dengan lebar 4 meter dan tinggi 2,5 meter.

1. Lokasi Perusahaan

UD. Mandiri berlokasi di Jalan Sultan Agung Desa Teluk Kecamatan Purwokerto Selatan 
Kabupaten Banyumas dengan batas sebagai berikut :
a. Sebelah Barat
: Rumah Warga
b. Sebelah Utara
: Jalan Raya
c. Sebelah Timur
: Area Persawahan
d. Sebelah Selatan
: Area Persawahan

2. Hasil Produksi

Adapun hasil produksi UD.Mandiri adalah kusen, pintu, jendela, lemari, kursi dan berbagai perabotan rumah tangga lainnya. Dalam proses produksi UD.Mandiri menggunakan kay u lokal dan kayu Kalimantan.

3. Wilayah Pemasaran

Wilayah Pemasaran UD.Mandiri yaitu ke daerah Pekalongan, Majenang, Cilacap, Tegal dan Jakarta.

4. Pekerja dan Jam Kerja

Pekerja di UD.Mandiri terdiri dari 6 orang pekerja yang bekerja pada bagian produksi. Lama kerja pekerja di UD.Mandiri adalah 8 jam kerja yang dimulai pukul 08.00 - 16.00 selama 6 hari kerja, 48 jam dalam seminggu.

5. Peralatan Kerja

Terdapat 4 (empat) mesin yang digunakan dalam proses produksi di UD.Mandiri yaitu Mesin Belah, Planner, Siku dan Bobok. Selain menggunakan mesin, proses produksi juga menggunakan peralatan pertukangan seperti : kampak, pahat, palu, gergaji, siku penggaris, serut, profil dan bor.

6. Bahan Baku

Bahan Baku yang digunakan di UD.Mandiri berasal dari Kayu Kalimantan dan Kayu Lokal. Jenis kayu yang digunakan adalah kayu kamper, kruing, bangker dan meranti.

7. Proses Produksi

Proses produksi pada UD. Mandiri melalui beberapa tahap, antara lain :

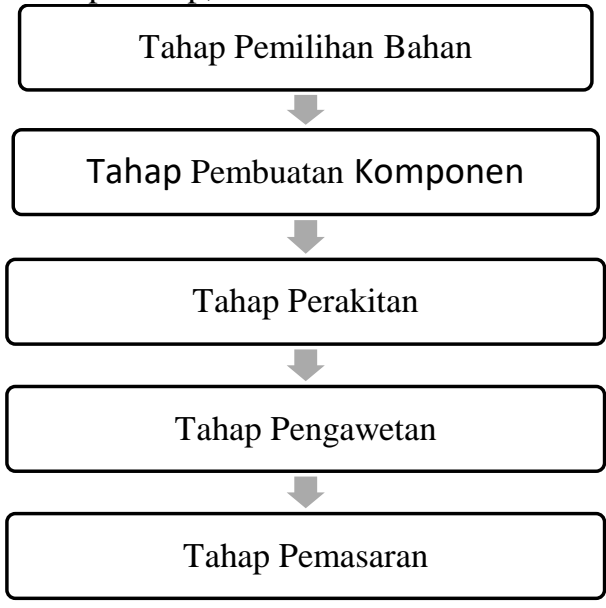

Gambar 4.1

Proses produksi

8. Upaya Pengendalian Kadar Debu

Pemilik UD.Mandiri belum melakukan upaya pengendalian kadar debu baik secara teknis maupun administratif.

\section{B. Data khusus}

1. Kadar Debu Total pada bagian produksi UD.Mandiri

Pengukuran kadar debu total pada bagian produksi di UD. Mandiri dilakukan pada tanggal 25 April 2018 pada pukul 09.00 12.00, dapat dilihat pada tabel 4.1.

Tabel 4.1 :Hasil pengukuran kadar debu total pada bagian produksi di UD.Mandiri di Desa Teluk Kecamatan Purwokerto Selatan Kabupaten Banyumas Tahun 2018

\begin{tabular}{llr}
\hline No. & Lokasi & $\begin{array}{c}\text { Hasil pengukuran } \\
\text { selama 15 menit } \\
\left(\mathrm{mg} / \mathrm{m}^{3}\right)\end{array}$ \\
\hline 1. & Titik 1 & 1,04 \\
2. & Titik 2 & 3,29 \\
3. & Titik 3 & 0,37 \\
4. & Titik 4 & 0,95 \\
5. & Titik 5 & 4,96 \\
\hline & Rata-rata & 2,12 \\
\hline
\end{tabular}

Hasil pengukuran kadar debu total memiliki range $0,37 \mathrm{mg} / \mathrm{m}^{3}-4,96 \mathrm{mg} / \mathrm{m}^{3}$ kadar debu total maksimum berada di titik 5 sebesar 4,96 mg/m ${ }^{3}$. Kadar debu total minimum berada pada titik 3 sebesar 0,37 $\mathrm{mg} / \mathrm{m}^{3}$. Rerata kadar debu total pada bagian produksi di UD.Mandiri Desa Teluk Kecamatan Purwokerto Selatan Tahun 2018 yaitu $2,12 \mathrm{mg} / \mathrm{m}^{3}$. Kadar debu total tersebut masih dibawah standar yang telah ditetapkan Peraturan Menteri Kesehatan Nomor 70 Tahun 2016 tentang Standar dan Persyaratan Kesehatan Lingkungan Kerja Industri kadar debu total dalam pengukuran debu rata-rata 8 jam adalah $10 \mathrm{mg} / \mathrm{m}^{3}$.

Kadar debu total maksimum berada pada titik 5 sebesar $4,96 \mathrm{mg} / \mathrm{m}^{3}$ hal ini disebabkan karena titik tersebut berada di dekat mesin pembelah yang menghasilkan banyak debu dan lokasinya jauh dari tembok terbuka. Kadar debu total minimum berada pada titik 3 sebanyak $0,37 \mathrm{mg} / \mathrm{m}^{3}$ hal ini dipengaruhi oleh lokasi titik pengambilan sampel yang berada di dekat mesin serut yang hanya sedikit menghasilkan debu.

Pekerja yang terpajan debu memiliki risiko untuk mengalami keluhan kesehatan dan penyakit, baik penyakit infeksi maupun non infeksi (kanker). Keluhan pernapasan banyak dijumpai dalam industri kayu. Selain keluhan pernapasan, dampak pajanan debu terhadap kesehatan yang sering dilaporkan adalah dermatitis, gangguan fungsi paru, dan beberapa jenis kanker pada saluran pernapasan. Mikroorganisme yang terdapat pada kayu juga dapat menyebabkan terjadinya 
keluhan dan gangguan kesehatan (Irjayanti, dkk., 2012).

Keluhan pernapasan yang terjadi dipengaruhi oleh ukuran debu. Debu yang berukuran 5-10 mikron akan masuk ke dalam saluran napas atas, 3-5 mikron masuk ke dalam saluran napas tengah, 1- 3 mikron dapat mencapai pembuluh di alveoli, 0,5-1 mikron akan menempel di alveoli, dan debu yang berukuran 0,1-0,5 akan melayang di atas alveoli (Depkes, 2014). Berbagai keluhan seperti hidung tersumbat, batuk, rinitis, dan asma juga dapat dialami oleh pekerja di industri kayu (Mirza, 2010).

Terdapat beberapa cara dalam mengendalikan bahaya di tempat kerja yaitu eliminasi, substitusi, engineering control, administrative control, alat pelindung diri (APD). Upaya pengendalian dengan cara eliminasi sangat sulit untuk dilakukan karena harus menghilangkan sumber bahaya secara keseluruhan. Pengendalian dengan cara substitusi yang dapat dilakukan pada UD.Mandiri yaitu mengganti bahan baku atau alat dengan jenis lain yang tidak terlalu berbahaya. Misalnya mengganti mesin yang sudah rusak atau kuno dengan mesin yang lebih canggih (Ade Saptari, 2011).

Upaya pengendalian secara Engineering control yang dapat dilakukan pada UD.Mandiri adalah melengkapi ruangan pada bagian produksi dengan penyedot debu bersifat lokal yang diletakkan di dekat mesin/sumber debu. (Ade Saptari, 2011).

Upaya pengendalian secara administrative yang dapat dilakukan pada UD.Mandiri antara lain : mengatur shift kerja dan waktu istirahat agar pekerja tidak terlalu lama terpapar debu, melakukan pengukuran untuk memantau konsentrasi debu, melakukan pemeriksaan kesehatan secara berkala pada pekerja(Ade Saptari, 2011).

Upaya pengendalian yang dilakukan sebagai upaya terakhir dalam melakukan pengendalian yaitu penggunaan alat pelindung diri (APD). Alat pelindung diri (pernapasan) wajib digunakan oleh semua pekerja di industri yang menghasilkan debu dalam proses produksinya. Jenis alat pelindung pernapasan yang dapat digunakan oleh pekerja industri kayu antara lain respirator, katrit, dan kanister (Peraturan Menteri Tenaga Kerja dan Transmigrasi Nomor 8 Tahun 2010 tentang Alat Pelindung Diri).

2. Suhu Udara pada bagian produksi UD.Mandiri

Pengukuran suhu udara pada bagian produksi di UD.Mandiri dilakukan pada tanggal 25 April 2018 pada pukul 09.00 12.00, dapat dilihat pada tabel 4.2.
Tabel 4.2 : Hasil pengukuran suhu udara pada bagian produksi di UD.Mandiri di Desa Teluk Kecamatan Purwokerto Selatan Kabupaten Banyumas Tahun 2018

\begin{tabular}{llr}
\hline No. & \multicolumn{1}{c}{ Lokasi } & Suhu $\left({ }^{0} \mathrm{C}\right)$ \\
\hline 1. & Titik 1 & 30,0 \\
2. & Titik 2 & 32,0 \\
3. & Titik 3 & 32,0 \\
4. & Titik 4 & 35,0 \\
5. & Titik 5 & 37,0 \\
\hline & Rata - rata & 33,2 \\
\hline
\end{tabular}

Berdasarkan hasil pengukuran suhu udara pada bagian produksi UD.Mandiri di Desa Teluk Kecamatan Purwokerto Selatan yang dilakukan pada 5 titik memiliki suhu udara memiliki range $30,0{ }^{\circ} \mathrm{C}-37,0{ }^{\circ} \mathrm{C}$ sehingga diperoleh rata-rata $33,2{ }^{\circ} \mathrm{C}$. Suhu tersebut dipengaruhi oleh kondisi ruangan yang kurang ventilasi dan mesin yang beroperasi selama 8 jam kerja. Menurut Suma'mur (2013, h.207) suhu nyaman orang Indonesia bekerja pada ruangan di industri adalah $24^{\circ} \mathrm{C}-26^{\circ} \mathrm{C}$ maka dapat disimpulkan bahwa hasil pengukuran suhu pada bagian produksi UD.Mandiri melebihi standar.

Suhu tertinggi berada pada titik 5 dengan suhu $37,0^{\circ} \mathrm{C}$, hal ini dipengaruhi karena di titik tersebut berada dekat dengan mesin yang beroperasi terus-menerus dan lokasinya jauh dari tembok terbuka maupun ventilasi. Suhu terendah berada pada titik 1 dengan suhu 30,0 ${ }^{\circ} \mathrm{C}$, hal ini dipengaruhi karena pada titik tersebut lokasinya dekat dengan tembok terbuka.

Suhu yang tinggi akan mempercepat terjadinya perubahan kadar gas atau polutan di udara. Semakin tinggi suhu udara, maka partikel akan menjadi semakin kering dan ringan. Suhu yang tinggi juga menyebabkan partikel lebih reaktif dan dapat bertahan lebih lama di udara (Salisa, 2011).

Hasil pengukuran suhu udara pada bagian produksi UD.Mandiri tergolong cukup tinggi. Kondisi ini dapat mempercepat pertumbuhan bakteri endotoksin yang terdapat pada kayu. Endotoksin merupakan racun yang dihasilkan oleh bakteri gram negatif. Biasanya, keberadaan endotoksin mengindikasikan adanya mould atau fungi (Rongo, et al., 2004). Fungi dapat ditemukan di semua tempat yang terdapat bahan organik, seperti kayu, kulit, gabus, rambut, dan lain sebagainya. Pada umumnya, fungi tumbuh dengan baik pada suhu $20{ }^{\circ} \mathrm{C}-35^{\circ} \mathrm{C}$ (Fitria, dkk., 2008).

Suhu udara pada tempat kerja yang terlalu panas dapat menyebabkan hipertermia, berkeringat banyak yang akhirnya nanti timbul 
dehidrasi. Gangguan suhu panas juga dapat menyebabkan heat cramps (kejang otot), heay syncope (denyut nadi menurun), heat exhausted (kelelahan akibat panas), heat stroke (detak jantung cepat). Pada pekerja dengan lingkungan suhu panas cenderung berakibat cepat letih, sering melakukan kesalahan, mengantuk, mengurangi kestabilan, cepat marah/emosi (Tri Cahyono, 2017).

Menurut Soeripto M (2009, h.299 h.310) terdapat beberapa cara yang dapat dilakukan untuk mengatasi permasalahan suhu yang tinggi pada bagian produksi, antara lain : a. Pengendalian secara umum

1)Training (pendidikan/latihan)

Pendidikan atau latihan diperuntukkan bagi calon tenaga kerja sebelum bekerja. Dalam pelatihan ini calon pekerja akan diberikan informasi tentang cara mengendalikan tekanan panas dan cara untuk mengendalikan resiko yang berhubungan dengan panas.

b. Pengendalian melalui penerapan Higiene 1)Penggantian cairan

Kehilangan air yang sangat banyak dari tubuh dalam bentuk keringat adalah untuk tujuan pendinginan dengan penguapan. Air minum harus disediakan bagi tenaga kerja yang bekerja di lingkungan tempat kerja panas. NIOSH menyarankan agar tenaga kerja minum sebanyak 150-200 cc setiap 15-20 menit.

2)Aklimatisasi

Setiap calon tenaga kerja yang akan bekerja di lingkungan tempat kerja panas harus melakukan penyesuaian fisiologis terhadap pajanan panas secara bertahap.

3)Self Determination

Pembatasan terhadap pajanan panas dimana tenaga kerja menghindari terhadap cuaca panas apabila ia sudah merasakan terpapar suhu panas secara berlebihan.

4) Gaya Hidup dan Status Kesehatan

Tenaga kerja harus tidur cukup dan berolahraga rutin.

5)Pakaian Kerja

Pakaian kerja untuk lingkungan tempat kerja panas sebaiknya dari bahan yang mudah menyerap keringat seperti katun, sehingga penguapan mudah terjadi.

c. Pengendalian secara khusus

1)Pengendalian secara Teknis

a) Mengurangi beban kerja

Mengurangi beban kerja dari berat ke beban kerja ringan dapat menurunkan tingkat tekanan panas.

b)Menurunkan suhu udara

Suhu udara dapat diturunkan dengan memasang ventilasi dengan cara pengenceran dan dengan pendinginan secara aktif.

c) Meningkatkan gerakan udara

$$
\text { Keuntungan dari peningkatan }
$$
gerakan udara adalah dapat mempertinggi penguapan dengan pendinginan.

d) Ganti pakaian

2)Pengendalian secara Administratif

a) Aklimatisasi

Aklimatisasi bertujuan agar tenaga kerja memiliki kemampuan yang lebih baik untuk bekerja di lingkungan tempat kerja panas.

b) Memperlambat kerja

Kecepatan pembentukan panas metabolisme dapat dikurangi apabila sejumlah pekerjaan yang sama dikerjakan dalam waktu yang lebih lama.

c) Membagi pekerjaan

Untuk mengurangi pajanan panas, pekerjaan dapat dibagi atau dikerjakan oleh beberapa orang dengan cara bergantian. Dengan demikian pemaparan terhadap panas bagi pekerja turun/ berkurang dalam waktu yang singkat.

3. Kelembapan Udara pada bagian produksi UD.Mandiri

Pengukuran kelembapan udara pada bagian produksidi UD.Mandiri Desa Teluk Kecamatan Purwokerto Selatan dilakukan pada tanggal 25 April 2018 pada pukul 09.00 - 12.00, dapat dilihat pada tabel 4.3.

Tabel 4.3 :Hasil pengukuran kelembapan udara pada bagian produksi UD.Mandiri Desa Teluk Kecamatan Purwokerto Selatan Kabupaten Banyumas Tahun 2018

\begin{tabular}{ccr}
\hline No. & Lokasi & Kelembaban $(\%)$ \\
\hline 1. & Titik 1 & 64,0 \\
2. & Titik 2 & 64,0 \\
3. & Titik 3 & 62,0 \\
4. & Titik 4 & 56,0 \\
5. & Titik 5 & 48,0 \\
\hline \multicolumn{2}{c}{ Rata - rata } \\
\hline
\end{tabular}

Berdasarkan hasil pengukuran kelembapan udara pada bagian produksi UD.Mandiri di Desa Teluk Kecamatan Purwokerto Selatan yang dilakukan pada 5 titik memiliki kelembapan udara dengan range $48 \%$ - $64 \%$, sehingga diperoleh ratarata $58,8 \%$. Standar kelembapan udara pada ruang kerja industri adalah $65 \%$ - 95\%, maka dapat disimpulkan bahwa hasil pengukuran kelembapan udara pada bagian produksi UD.Mandiri masih dibawah standar.

Kelembapan udara maksimum berada di titik 1 dan 2 dengan kelembapan $64 \%$ 
sedangkan kelembapan udara minimum berada pada titik 5 dengan kelembapan $48 \%$. Semakin tinggi uap air di udara maka nilai kelembapan akan semakin tinggi. Nilai kelembapan yang tinggi membuat polutan semakin mudah untuk bereaksi dengan air sehingga berat jenis polutan akan meningkat. Kelembapan yang tinggi merupakan kondisi yang ideal bagi kapang dan mikroorganisme lainnya untuk berkembang biak. Sedangkan kelembapan yang terlalu rendah dapat mempengaruhi terjadinya berbagai gangguan seperti iritasi membran mukosa, mata kering, dan sinus (Fitria, dkk., 2008).

Menurut H.J Mukono (1997) kelembapan relatif lebih atau sama dengan $80 \%$ di daerah tercemar akan terjadi peningkatan efek korosif karena kelembapan yang tinggi maka kadar uap air di udara dapat bereaksi dengan pencemar udara, menjadi zat lain yang tidak berbahaya atau menjadi pencemar sekunder.

4. Kecepatan Angin pada bagian produksi UD.Mandiri

Pengukuran kecepatan angin pada bagian produksi UD.Mandiri dilakukan pada tanggal 25 April 2018 pada pukul 09.00 - 12.00, dapat dilihat pada tabel 4.4 .

Tabel 4.4 : Hasil pengukuran kecepatan angin pada bagian produksi UD.Mandiri di Desa Teluk Kecamatan Purwokerto Selatan Kabupaten Banyumas Tahun 2018

\begin{tabular}{ccr}
\hline No. & Lokasi & \multicolumn{2}{c}{$\begin{array}{c}\text { Kecepatan } \\
\text { Angin }(\mathrm{m} / \mathrm{s})\end{array}$} \\
\hline 1. & Titik 1 & 0,28 \\
2. & Titik 2 & 0,10 \\
3. & Titik 3 & 0,10 \\
4. & Titik 4 & 0,18 \\
5. & Titik 5 & 0,16 \\
\hline & Rata - rata & 0,16 \\
\hline
\end{tabular}

Berdasarkan hasil pengukuran kecepatan angin pada bagian produksi UD.Mandiri di Desa Teluk Kecamatan Purwokerto Selatan yang dilakukan pada 5 titik memiliki kecepatan angin dengan range $0,1-0,28 \mathrm{~m} / \mathrm{s}$, sehingga diperoleh rata-rata $0,16 \mathrm{~m} / \mathrm{s}$. Hasil rata-rata kecepatan angin tersebut sudah sesuai dengan standar kecepatan angin yaitu 0,15 $0,25 \mathrm{~m} / \mathrm{s}$. Keadaan tersebut dapat dipengaruhi oleh keadaan pintu yang terbuka lebar dan kondisi ruangan yang terbuka sehingga udara luar ruangan masuk ke ruang produksi.

Akibat pergerakan udara maka terjadi suatu proses penyebaran yang dapat mengakibatkan pencemaran dari bahan pencemar udara, sehingga kadar suatu pencemar pada jarak tertentu dari sumber akan mempunyai kadar yang berbeda. Demikian juga dengan arah dan kecepatan angin yang dapat mempengaruhi kadar pencemar setempat .(Mukono 2008,h.10). Untuk menjaga agar pertukaran udara pada ruang kerja dapat berjalan dengan baik maka untuk ruangan kerja yang tidak ber $\mathrm{AC}$ harus memiliki lubang ventilasi minimal $15 \%$ dari luas lantai dengan menerapkan sistim ventilasi silang.

5. Arah Angin pada bagian produksi UD.Mandiri Pengukuran arah angin pada bagian produksi UD.Mandiri dilakukan pada tanggal 25 April 2018 pada pukul 09.00 - 12.00, dapat dilihat pada tabel 4.5 .

Tabel 4.5 :Hasil pengukuran arah angin pada bagian produksi UD.Mandiri di Desa Teluk Kecamatan Purwokerto Selatan Kabupaten Banyumas Tahun 2018

\begin{tabular}{lll}
\hline No. & \multicolumn{1}{c}{ Lokasi } & Arah Angin $\left({ }^{0}\right)$ \\
\hline 1. & Titik 1 & Utara $\left(0^{0}\right)$ \\
2. & Titik 2 & Timur $\left(90^{0}\right)$ \\
3. & Titik 3 & Barat $\left(270^{\circ}\right)$ \\
4. & Titik 4 & Utara $\left(0^{0}\right)$ \\
5. & Titik 5 & Utara $\left(0^{0}\right)$ \\
\hline & Modus & Timur Laut $\left(72^{0}\right)$ \\
\hline
\end{tabular}

Arah angin pada saat dilakukan pengukuran pada bagian produksi UD.Mandiri Desa Teluk Kecamatan Purwokerto Selatan sebanyak 5 titik hasilnya berbeda-beda namun arah angina lebih dominan kearah Timur Laut . Arah angin yang berbeda-beda pada masingmasing titik ini dipengaruhi oleh beberapa faktor di antaranya dipengaruhi oleh lokasi pabrik yang berbatasan dengan area persawahan yang berada pada batas bagian Selatan, kontruksi ruangan yang masih belum tertata, masih banyak lubang di dinding ruangan, udara dari luar rungan yang masuk kedalam ruangan, peletakan bahan yang belum rapi.

\section{KESIMPULAN}

Berdasarkan hasil dan pembahasan tentang kadar debu udara pada bagian produksi UD.Mandiri yang telah diuraikan dapat diambil kesimpulan sebagai berikut :

1. Kadar debu total maksimum berada di titik 5 sebesar $4,96 \mathrm{mg} / \mathrm{m}^{3}$. Kadar debu total minimum berada pada titik 3 sebesar 0,37 $\mathrm{mg} / \mathrm{m}^{3}$. Rerata kadar debu total pada bagian produksi $2,12 \mathrm{mg} / \mathrm{m}^{3}$

2. Suhu udara maksimum berada di titik 5 dengan suhu $37,0{ }^{\circ} \mathrm{C}$. Suhu udara minimum berada pada titik 1 dengan suhu $30,0{ }^{\circ} \mathrm{C}$. Rerata suhu udara pada bagian produksi 33,2 ${ }^{0} \mathrm{C}$. 
3. Kelembapan udara maksimum berada di titik 1 dan 2 dengan kelembapan sebesar 64,0\%. Kelembapan udara minimum berada pada titik 5 dengan kelembapan sebesar 48,0\%. Rerata kelembapan udara pada bagian produksi $58,8 \%$.

4. Kecepatan angin maksimum berada di titik 1 sebesar $0,28 \mathrm{~m} / \mathrm{s}$. Kecepatan angin minimum berada pada titik 2 dan 3 sebesar $0,10 \mathrm{~m} / \mathrm{s}$. Rerata kecepatan angin pada bagian produksi $0,16 \mathrm{~m} / \mathrm{s}$.

5. Arah angin pada bagian produksi UD.Mandiri Desa Teluk Kecamatan Purwokerto Selatan lebih dominan ke arah Timur Laut.

\section{DAFTAR PUSTAKA}

Ade Saptari. 2011. Analisis Pengendalian Debu Pada Industri Mebel di Area Produksi Pre Cut PT X. Skripsi. Jakarta : Fakultas Kesehatan Masyarakat Universitas Indonesia.

Annas Restu Barokah. 2013. Studi Kadar Debu Pada Pekerja Bagian Repair Di PT. Wana Makmur Sejahtera Kabupaten Purbalingga. KTI. Purwokerto : Kementerian Kesehatan RI Politeknik Kesehatan Semarang Jurusan Kesehatan Lingkungan Purwokerto.

Anonym. 2016. Makalah Pembuatan Kusen Pintu Dan Jendela. at coretannduwir.blogspot.ac.id. Diakses pada tanggal 4 Januari 2018.

Chandra, Budiman. 2006. Pengantar Kesehatan Lingkungan. Jakarta : EGC

Fardiaz, Srikandi. 2003. Polusi Air Dan Udara.Yogyakarta : Kanisius

Jurnal Kesehatan Lingkungan. 2006. Paparan Debu Kayu dan Gangguan Fungsi Paru pada Pekerja Mebel (Studi di PT. Alis Jaya Ciptatama). at ejournal.undip.ac.id, diakses pada tanggal 8 Mei 2018.

\section{Hubungan Kadar Debu}

Terhirup (Respirable) dengan Kapasitas Vital Paksa Paru pada Pekerja Mebel Kayu di Kota Jayapura. At eprints.undip.ac.id, diakses pada tanggal 8 Mei 2018.
. 2015. Hubungan Karakteristik

Pekerja Dan Kadar Debu Total Dengan

Keluhan Pernapasan Pada Pekerja

Industri Kayu X Di Kabupaten

Lumajang. at journal.unair.ac.id, diunduh pada tanggal 3 Januari 2018.

Mukono, HJ. 2008. Pencemaran Udara dan Pengaruhnya Terhadap Gangguan Saluran Pernapasan. Surabaya : Airlangga.

Nurohim, Taufik. 2014. Studi Deskriptif Kadar Debu Total Pada Bagian Produksi Pabrik Kayu UD. Kartika Sari Di Desa Prigi Kecamatan Sigaluh Kabupaten Banjarnegara Tahun 2014. KTI. Purwokerto : Kementerian Kesehatan RI Politeknik Kesehatan Semarang Jurusan Kesehatan Lingkungan Purwokerto.

Mustari Retnawati. 2013. Hubungan Paparan Debu Dengan Kapasitas Paru Pekerja Bagian Raw Mill Di PT. Holcim Indonesia Tbk Cilacap Plant Tahun 2013. KTI. Purwokerto : Kementerian Kesehatan RI Politeknik Kesehatan Semarang Jurusan Kesehatan Lingkungan Purwokerto.

Makara Seri Kesehatan. 2008. Kualitas Udara dalam Ruang Perpustakaan Universitas X Ditinjau dari Kualitas Biologi, Fisik, dan Kimiawi. at journal.ui.ac.id, diakses 4 Januari 2018.

Peraturan Menteri Kesehatan Nomor 70 Tahun 2016 Tentang Standar dan Persyaratan Kesehatan Lingkungan Kerja Industri.

Peraturan Menteri Tenaga Kerja dan Transmigrasi Nomor 8 Tahun 2010 Tentang Alat Pelindung Diri.

Peraturan Pemerintah RI Nomor 41 Tahun 1999 Tentang Pengendalian Pencemaran Udara.

Riyadi, Slamet, Al. 1982. Pencemaran Udara. Surabaya : Usaha Nasional. 
Rosmawati, Azizah. 2013. Studi Deskriptif Kualitas Udara Di Tempat Pembakaran Batu Kapur Di Desa Karangdawa Kecamatan Cilongok Kabupaten Banyumas. KTI. Purwokerto : Kementerian Kesehatan RI Politeknik Kesehatan Semarang Jurusan Kesehatan Lingkungan Purwokerto.

Salisa, S. 2011. Paparan Asap dari Aktivitas Pengasapan Ikan Terhadap Keluhan Mata, Pernapasan, dan Fungsi Paru. Skripsi. Surabaya : Fakultas Kesehatan Masyarakat Universitas Airlangga.

Sastrawijaya, Tresna. 2000. Pencemaran Lingkungan. Jakarta : Rineka Cipta.

Soedomo, Moestikahadi. 2001. Pencemaran Udara. Bandung : ITB

Soeripto, M. 2009. Higiene Industri. Jakarta : Balai Penerbit FKUI

Suma'mur, P.K. 2009. Higiene Perusahaan dan Kesehatan Kerja. Cetakan ke sembilan. Jakarta : CV Gunung Agung
Suryani, M. 2005. Analisis Faktor Risiko Paparan Debu Kayu terhadap Gangguan Fungsi Paru pada Pekerja Industri Pengolahan Kayu PT. Surya Sindoro Sumbing Wood Industry Wonosobo. Tesis. Semarang : Fakultas Kesehatan Masyarakat Universitas Diponegoro.

Tri Cahyono. 2017. Panduan Penulisan Tugas Akhir. Purwokerto : Kementerian Kesehatan RI Politeknik Kesehatan Semarang Jurusan Kesehatan Lingkungan Purwokerto

Yogyakarta : Andi.

2017. Penyehatan Udara.

Wardhana, W.A., 2004. Dampak Pencemaran Lingkungan. Cetakan ke tiga. Yogyakarta : Andi Offset.

Yunus, F. 2006. Dampak Debu Industri pada Paru Pekerja dan Pengendaliannya. Fakultas Kedokteran Universitas Indonesia Bagian Pulmonologi. at kalbefarma.com, diakses 4 Januari 2018. 